\title{
Magnetic Properties of $\mathrm{Nd}_{12} \mathrm{Fe}_{82} \mathrm{~B}_{6}$ and $\mathrm{Nd}_{14} \mathrm{Fe}_{80} \mathrm{~B}_{6}$ Powders Obtained by High Temperature Milling
}

\author{
W. KaszuWara And B. Michalski \\ Faculty of Materials Science and Engineering, Warsaw University of Technology \\ Wołoska 141, 02-507 Warsaw, Poland
}

\begin{abstract}
The present paper describes a comparison of magnetic properties of $\mathrm{Nd}_{12} \mathrm{Fe}_{82} \mathrm{~B}_{6}$ and $\mathrm{Nd}_{14} \mathrm{Fe}_{80} \mathrm{~B}_{6}$ powders obtained by a new method of processing of $\mathrm{Nd}-\mathrm{Fe}-\mathrm{B}$ powders - high temperature milling. In this method the milling operation is carried out, entirely or only in the final stage, at high temperatures, so that the destruction of the $\mathrm{Nd}_{2} \mathrm{Fe}_{14} \mathrm{~B}$ phase and its recombination occur simultaneously. In this way a powder with good magnetic properties immediately after milling was obtained. In the present experiments, the powder was subjected to high-energy milling for $17 \mathrm{~h}$ (until the material becomes amorphous) and then, the milling was continued for $0.5 \mathrm{~h}$ with the powder container being heated to an appropriate temperature or milled at high temperature during whole time of the process. Diffraction examinations have shown that the powder processed in this way contains the $\mathrm{Nd}_{2} \mathrm{Fe}_{14} \mathrm{~B}$ phase. Its magnetic properties appear to depend on the applied temperature or milling time (at optimum temperature). The used method of processing leads to obtaining high-coercivity Nd-Fe-B powders. The magnetic properties of the material thus produced, in particular its coercivity, strongly depend on the milling temperature and milling time.
\end{abstract}

PACS: $75.50 . \mathrm{Tt}, 75.50 . \mathrm{Ww}, 81.20 . \mathrm{Wk}$

\section{Introduction}

Milling at elevated or high temperature has not often been used. This is probably so because of the severe technical problems associated with heating the powder containers when it is in motion and with ensuring, under these conditions, an appropriate atmosphere that protects the material being milled. In the literature, we can only find a few examples of milling metallic powders at elevated temperatures and the available reports only describe this process in general terms. A research group at the University of Wollongong describes a method in which the milling operation is assisted with electric discharges ignited between a mill ball and the surface of the container $[1,2]$. This experiment gave very interesting results. Depending on the treated material and the milling parameters, the rate of refinement of the powders could be increased, the powders agglomerated or new phases were formed, other than those occurring under the equilibrium conditions. The decisive factor was here the electric discharge, but the increase of the temperature due to this discharge was not analyzed. There are also reports [3] on high-temperature milling (up to $503 \mathrm{~K}$ ) of nanocomposite $\mathrm{Cu}-\mathrm{Ag}$ powders.

High-temperature milling of hard magnetic Nd-Fe-B powders has first been described in our earlier papers $[4,5]$. We demonstrated that, by conducting the milling process, or only the final stage of the process, at an appropriately high temperature, it was possible to obtain a high-coercivity powder.
At the present, most magnetic $\mathrm{Nd}-\mathrm{Fe}-\mathrm{B}$ materials are produced by sintering. There is however also demand for hard magnetic powders intended for the manufacture of bonded magnets. Such powders can be produced by spraying the alloy in the melted state, or by the refinement of the alloy in the solid state followed by an appropriate modification of its structure. The method most important from the technical point of view consists of milling rapidly cooled and then thermally processed ribbons. The high-coercive powders may also be produced using the hydrogenation, disproportionation, desorption, recombination (HDDR) method, mechanical alloying or mechanical milling. In the last two methods, the basic operation consists of long-term high-energy milling which yields a mixture of nanocrystalline and amorphous phases. In the mechanical alloying it is the powders composed of the constituent elements of the alloy which are subjected to milling, whereas the mechanical synthesis utilizes the alloy in the powdered form. In both methods the powder mixtures obtained after milling are subjected to annealing in order to produce the $\mathrm{Nd}_{2} \mathrm{Fe}_{14} \mathrm{~B}$ phase with nanometric grains.

In most of the methods described above the structure of the high-coercive $\mathrm{Nd}-\mathrm{Fe}-\mathrm{B}$ material is achieved in two stages: first, the $\mathrm{Nd}_{2} \mathrm{Fe}_{14} \mathrm{~B}$ phase is decomposed to obtain a structure entirely amorphous or with nanocrystalline precipitates, then the $\mathrm{Nd}_{2} \mathrm{Fe}_{14} \mathrm{~B}$ phase is recrystallized to form grains with nanocrystalline sizes.

The present study is devoted to a new method of producing high-coercivity $\mathrm{Nd}-\mathrm{Fe}-\mathrm{B}$ powders in which the alloy is milled at a high temperature. The method permits 
combining the two stages of the process mentioned above (destruction and then reconstruction of the $\mathrm{Nd}_{2} \mathrm{Fe}_{14} \mathrm{~B}$ phase with the desired microstructure) in a single operation.

In the present experiments the highly coercive $\mathrm{Nd}-\mathrm{Fe}-\mathrm{B}$ powders were obtained by mechanical milling at a high temperature. The aim of the study was to find how the Nd content in the alloy affects the course and results of this process.

\section{Experimental}

The materials subjected to high-temperature milling were alloys with the chemical compositions $\mathrm{Nd}_{12} \mathrm{Fe}_{82} \mathrm{~B}_{6}$ and $\mathrm{Nd}_{14} \mathrm{Fe}_{80} \mathrm{~B}_{6}$, cast in the form of plates and then ground to obtain a powder with a grain size below $1 \mathrm{~mm}$. The milling process was conducted in a vibration ball mill using an argon protective atmosphere. The experiments were conducted using two different procedures. In process I, the powder was milled without heating for $17 \mathrm{~h}$, and then, while the milling was continued, the container with the powder was heated to the desired temperature (during about $30 \mathrm{~min}$ ) and maintained at this temperature for $30 \mathrm{~min}$. In process 2 , the entire milling process was conducted at a high temperature. After the high-temperature milling was completed, the container with the powder inside was cooled to room temperature during about $5 \mathrm{~min}$. The container being cooled, the powder was removed from it by short-time milling (for about $20 \mathrm{~min}$ ) in the environment of toluene. The temperature was measured outside the container. The magnetic properties of the powders thus produced were examined in a Lake Shore vibrating sample magnetometer. The powders were also examined by X-ray diffraction (XRD) using the $\mathrm{Cu} K_{\alpha}$ radiation. The size of the $\mathrm{Nd}_{2} \mathrm{Fe}_{14} \mathrm{~B}$ crystallites was determined using the Scherrer method for the (202) peak.

\section{Results}

Milling the $\mathrm{Nd}_{12} \mathrm{Fe}_{82} \mathrm{~B}_{6}$ and $\mathrm{Nd}_{14} \mathrm{Fe}_{80} \mathrm{~B}_{6}$ alloys with heating applied during the final stage of the process (process 1) gives powders with good magnetic properties. The difference between the coercivity and remanence values between these two alloys are due primarily to the different $\mathrm{Nd}$ contents. The results also evidently indicate that these values depend on the milling temperature. In both materials, the coercivity initially increases with increasing milling temperature (Fig. 1). We can suppose that within this temperature range the $\mathrm{Nd}_{2} \mathrm{Fe}_{14} \mathrm{~B}$ phase crystallizes from the amorphous phase and its share increases. In the alloy with $14 \%$ of $\mathrm{Nd}$, the coercivity reaches its maximum value at a markedly lower temperature than in the alloy with $12 \% \mathrm{Nd}$ but above about $540{ }^{\circ} \mathrm{C}$ it begins to decrease. The coercivity of the $\mathrm{Nd}_{12} \mathrm{Fe}_{82} \mathrm{~B}_{6}$ alloy, on the other hand, only decreases when the temperature exceeds $600^{\circ} \mathrm{C}$.

The remanence of the $\mathrm{Nd}_{14} \mathrm{Fe}_{80} \mathrm{~B}_{6}$ alloy depends less on the milling temperature than that of the $\mathrm{Nd}_{12} \mathrm{Fe}_{82} \mathrm{~B}_{6}$

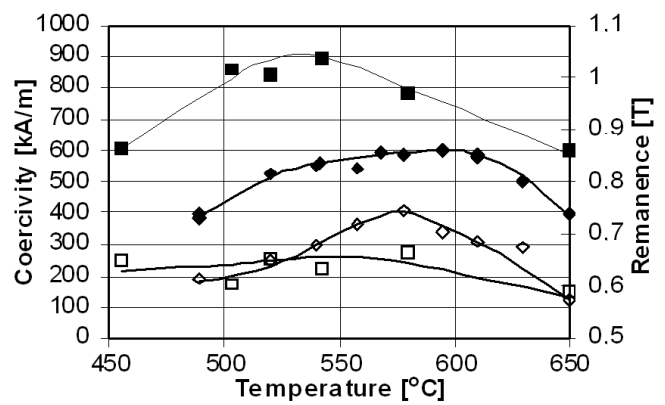

Fig. 1. Effect of the temperature maintained during the final stage of the milling operation (process 1) on the coercivity $(\checkmark)$ and remanence $(\diamond)$ of the $\mathrm{Nd}_{12} \mathrm{Fe}_{82} \mathrm{~B}_{6}$ and coercivity $(\boldsymbol{\square})$ and remanence of $\mathrm{Nd}_{14} \mathrm{Fe}_{80} \mathrm{~B}_{6}(\square)$ powders.

alloy (Fig. 1). In both alloys, the remanence decreases after the milling temperature exceeds about $580^{\circ} \mathrm{C}$, which may probably be attributed to the further growth of the $\mathrm{Nd}_{2} \mathrm{Fe}_{14} \mathrm{~B}$ phase grains.

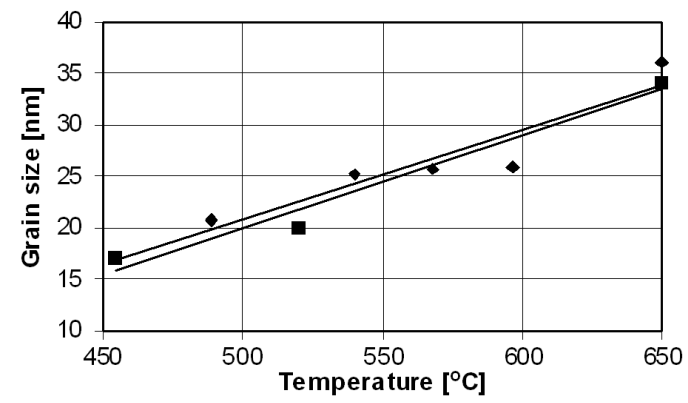

Fig. 2. Effect of the temperature maintained during the final stage of the milling operation (process I) on the grain size of the $\mathrm{Nd}_{2} \mathrm{Fe}_{14} \mathrm{~B}$ phase in the $\mathrm{Nd}_{12} \mathrm{Fe}_{82} \mathrm{~B}_{6}$ $(\checkmark)$ and $\mathrm{Nd}_{14} \mathrm{Fe}_{80} \mathrm{~B}_{6}(\boldsymbol{\square})$ powders.

The measured crystallite sizes of this phase present in the powders of the two alloys milled at various temperatures shown in Fig. 2 indicate that they increase with increasing milling temperature. After interpolating the results obtained for each of the two alloys with a straight line we can see that they differ only slightly from one another. Hence it can be concluded that the grain size of the two alloys varies with the milling temperature in the same manner. Therefore, the difference in the temperature dependence of the magnetic properties between the two alloys must be due to their different phase structure.

The alloy with $12 \%$ of $\mathrm{Nd}$ should contain, almost exclusively, the $\mathrm{Nd}_{2} \mathrm{Fe}_{14} \mathrm{~B}$ phase, whereas the alloy with the $14 \% \mathrm{Nd}$ content, besides this phase also contains an $\mathrm{Nd}$-rich phase which insulates magnetically the $\mathrm{Nd}_{2} \mathrm{Fe}_{14} \mathrm{~B}$ grains. Figure 3 shows the results of the diffraction phase analysis of the powders of the two alloys milled at a temperature of $520^{\circ} \mathrm{C}$ and $650{ }^{\circ} \mathrm{C}$.

We can see in Fig. 3 that the diffraction peaks obtained for the $\mathrm{Nd}_{12} \mathrm{Fe}_{82} \mathrm{~B}_{6}$ alloy are more intensive and separated 


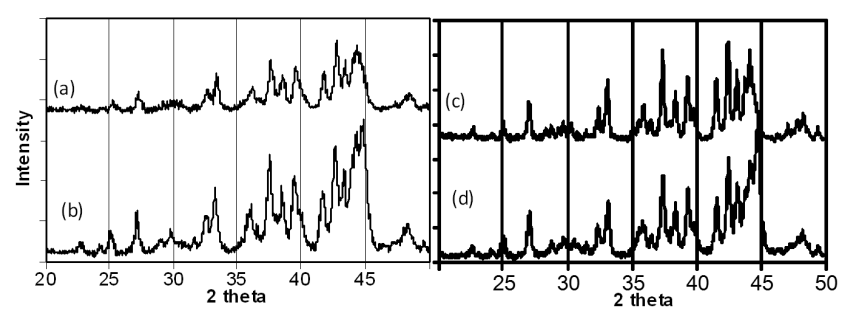

Fig. 3. Diffraction phase analysis of the $\mathrm{Nd}_{14} \mathrm{Fe}_{80} \mathrm{~B}_{6}$ powder milled at $520^{\circ} \mathrm{C}$ (a), $650^{\circ} \mathrm{C}$ (c) and of the $\mathrm{Nd}_{12} \mathrm{Fe}_{82} \mathrm{~B}_{6}$ powder milled at $520^{\circ} \mathrm{C}(\mathrm{b}), 650^{\circ} \mathrm{C}(\mathrm{d})$.

more clearly. We can also see that this material contains $\alpha$-Fe precipitates. The powder of this material is composed of microsized particles with nanosized grains. This makes it impossible to examine precisely its microstructure by e.g. electron microscopy.

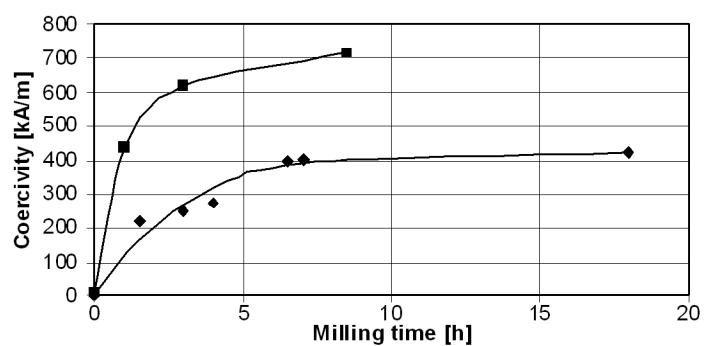

Fig. 4. Effect of the milling time (process II) of the $\mathrm{Nd}_{12} \mathrm{Fe}_{82} \mathrm{~B}_{6}$ powder at temperature $600^{\circ} \mathrm{C}(\checkmark)$ and of the $\mathrm{Nd}_{14} \mathrm{Fe}_{80} \mathrm{~B}_{6}$ powder at temperature $520^{\circ} \mathrm{C}(\boldsymbol{\square})$ on the coercivity.

The results of examining the effect of the milling time on the coercivity of the powders produced by process II (i.e., milled at a high temperature during the entire process) are shown in Fig. 4. In both the alloys, this dependence appeared to be similar, namely the coercivity initially increases with increasing milling time and then stabilizes at a level dependent on the chemical composition of the alloy. The maximum coercivity values are lower than those obtained in both alloys by process I. It is possible that the powder being milled is contaminated with the materials of the mill balls and of the powder container (high-alloy steel), or that neodymium from the alloy reacts with these materials. The degree of this contamination can be expected to depend on the time of milling conducted at a high temperature, which will explain why process II gives the material with worse magnetic properties. When comparing now the role of the $\mathrm{Nd}$ content we can see that the coercivity of the $\mathrm{Nd}_{14} \mathrm{Fe}_{80} \mathrm{~B}_{6}$ alloy during the initial stage of the milling process increases in a much shorter time than is the case in the $\mathrm{Nd}_{12} \mathrm{Fe}_{82} \mathrm{~B}_{6}$ alloy. With the $14 \% \mathrm{Nd}$ content, the microstructure favorable for good magnetic properties is formed more easily, i.e., at a lower temperature and a constant longer milling time (process I) or at a constant temperature and a shorter milling time (process II).

\section{Summary}

Milling the $\mathrm{Nd}-\mathrm{Fe}-\mathrm{B}$ powders assisted with high-temperature heating gives a material with good magnetic properties immediately after the milling operation. Two processes with differing heating schedules were examined and better results were obtained with process I, i.e. milling at room temperature until the powder mixture becomes amorphous and then continuing the milling operation at a high temperature to let the $\mathrm{Nd}_{2} \mathrm{Fe}_{14} \mathrm{~B}$ phase to crystallize. In the alloy with the 14 at. $\% \mathrm{Nd}$ content, which ensures the occurrence of an additional Nd-rich phase, it appeared easier to achieve good magnetic properties: process I enables the $\mathrm{Nd}_{14} \mathrm{Fe}_{80} \mathrm{~B}_{6}$ alloy to achieve the best properties at a lower temperature than is the case in the $\mathrm{Nd}_{12} \mathrm{Fe}_{82} \mathrm{~B}_{6}$ alloy, whereas in process II, the $\mathrm{Nd}_{14} \mathrm{Fe}_{80} \mathrm{~B}_{6}$ alloy achieves the improvement of its magnetic properties in a much shorter time during the initial stage of the milling operation.

\section{Acknowledgments}

This work was supported by the Polish Ministry of Science and Higher Education, project no. N N507 475537.

\section{References}

[1] A. Calka, D. Wexler, Nature 419, 147 (2002).

[2] A. Calka, Rev. Adv. Mater. Sci. 18, 398 (2008).

[3] S. Zghal, R. Twesten, Fang Wu, P. Bellon, Acta Mater. 50, 4711 (2002).

[4] W. Kaszuwara, B. Michalski, to be published in Lat. Am. Phys. Educ.

[5] W. Kaszuwara, B. Michalski, Inżynieria Materiałowa 179, 9 (2011) (in Polish). 